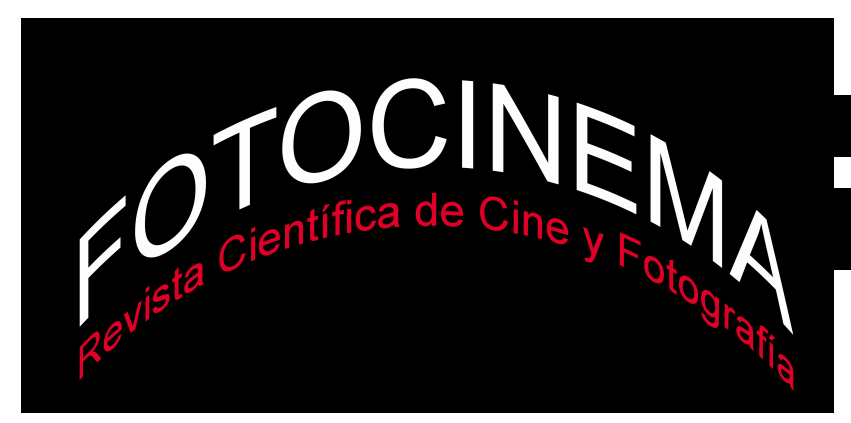

\title{
Arte e ideología en el cine de S. M. Eisenstein
}

\section{Art and ideology in S. M. Eisenstein's movies}

\author{
Daniel C. Narváez Torregrosa \\ Universidad de Burgos, España \\ dcnarvaez@ubu.es
}

\section{Resumen:}

Eisenstein, de cuyo nacimiento se cumplen cien años, es considerado uno de los más grandes cineastas de la Historia. Comprometido con las ideas bolcheviques y partidario de la Revolución de Octubre, quiso utilizar el cine como un vehículo más en la concienciación de las masas. Si bien se enfrentó a los sectores más ortodoxos del estalinismo, Eisenstein supo en todo momento llevar a la práctica una serie de ideas teóricas relacionadas con el sonido y el color. La puesta en práctica de éstas, no solo sirvieron para los fines ideológicos, sino que además convirtieron sus películas en auténticas obras de arte. Para ello no solo investigó en artes plásticas y teoría del color, sino que también optó por introducir en su obra referencias a otras culturas (como el Kabuki), artistas de vanguardia (Kandinsky) y músicos como Prokofiev. En el presente artículo se analizan las conexiones de Eisenstein con todos ellos y sobre todo la puesta en escena de estas ideas tan revolucionarias.

\begin{abstract}
:
Eisenstein, who was born hundred years ago, is considered one of the greatest filmmakers in History. Committed to Bolshevik ideas and as supporter of the October Revolution, he wanted to use film as another vehicle in the awareness of the masses. Although he faced the most orthodox sectors of Stalinism, Eisenstein knew at all times to put into practice a series of theoretical ideas related to sound and color. The implementation of these, not only served for ideological purposes, but also converted their films into authentic works of art. For this, he not only researched in arts and color theory, but also chose to introduce in his work references to other cultures (such as the Kabuki), avant-garde artists (Kandinsky) and musicians such as Prokofiev. The present essay analyzes the connections between Eisenstein and all of them, and specially how he performed these revolutionary ideas.
\end{abstract}

\section{Palabras clave:}

Eisenstein; Realismo socialista; Kandinsky, teoría del color; montaje.

Keywords:

Eisenstein; Socialist Realism; Kandinsky; Color Theory; Editing. 


\section{Introducción}

El valor de Eisenstein como uno de los grandes maestros del séptimo arte es innegable y sigue generando al día de hoy una amplia producción de artículos y libros tanto académicos como generalistas. Los estudios más conocidos, realizados por Goodwin (1995) y Bordwell (1996), han prestado atención a las relaciones del cine de Eisenstein con los aspectos ideológicos y narrativos respectivamente.

Las películas de Eisenstein se siguen proyectando en retrospectivas y ciclos dedicados al cineasta ruso, y las obras teóricas escritas por él mismo se reeditan constantemente, al mismo tiempo que la accesibilidad a archivos online permite conocer cada vez más material de su autoría.

Eisenstein fue un director de cine comprometido con su oficio y con su tiempo. Compromiso que le llevó a teorizar sobre los aspectos formales y las posibilidades estéticas del cine, junto al valor del mismo para transmitir una ideología política, en su caso, el socialismo revolucionario. Coetáneo a movimientos pictóricos como el Rayonismo o Sota de diamantes; la propuesta de la Vkhutemas ${ }^{1}$ y los acontecimientos que generaron la Revolución de Octubre de 1917, su cine -tanto desde la perspectiva teórica como de la práctica- no podía sustraerse a la experimentación y la propuesta de nuevos caminos.

Eisenstein manifestó que el cine sería "una maravillosa variedad de arte que fundirá en un todo e incorporará a la pintura y al drama, a la música y a la escultura, la arquitectura y la danza, el paisaje y el hombre, la imagen y la palabra” (Eisenstein, 1990), en definitiva, una obra de arte total como hasta el momento no se había realizado.

Partiendo de estas palabras del cineasta, se analiza en primer lugar la relación de sus filmes con la ideología del momento, que fue fluctuando desde el socialismo revolucionario de la primera etapa de la Revolución Bolchevique hasta el férreo autoritarismo de la época de Stalin, dejando claro que Eisenstein. En segundo lugar, se presta una especial atención a las propuestas estéticas de

${ }^{1}$ Acrónimo de Talleres de Enseñanza Superior del Arte y de la Técnica. 
Eisenstein en cuestiones innovadoras como el empleo de la música y el color. En los dos casos, se recurre al análisis de secuencias de sus filmes más emblemáticos.

\section{La Revolución de Octubre y las primeras realizaciones de Eisenstein}

La Revolución Bolchevique de Octubre trajo una influencia liberadora en el arte y la cultura rusa. En este momento surgieron una serie de artistas, poetas, músicos y cineastas inspirados por la Revolución que encontraron una gran libertad cultural promovida por los bolcheviques liderados por Lunatcharsky, intelectual con una visión panorámica de la cultura y del arte. Su influencia se hizo extensiva al Comité Central del Partido Bolchevique y en el decreto, emanado de este, el 16 de junio de 1925: Sobre la política del partido en materia de literatura artística.

Los principales artistas de la vanguardia rusa apoyaron la Revolución, y algunos de ellos como Malevich, Tatin, Kandinsky, Rodchenko, y otros, tuvieron una intensa actividad política, influenciados de una parte por las proclamas de Maiakovski, y de otra por las propias palabras de Lenin:

Vosotros los artistas sois unos individualistas obstinados; id a las masas; id a las fábricas y a los talleres. Allí recibiréis impulsos nuevos para vuestro trabajo creador, allí descubriréis lo que necesita en cada caso el proletariado (Lenin, 1975, p. 227).

Parte de esta renovación cultural fue la formación del Proletkult, organización destinada a culturizar a las masas cuya función quedó expresada en el manifiesto sobre el arte aprobado y difundido por el Comité Central de esta organización en 1923:

El arte debe constituir una parte intrínseca de la vida cotidiana, ya sea en las formas activamente figurativas (manifiestos, anuncios, teatro de agitación y propaganda, cine), ya sea en las formas materialmente organizativas (cultura psicofísica, organización de espectáculos de masas, fiestas, desfiles y 
manifestaciones, es decir, el ambiente material en el que se desarrolla la vida cotidiana y la construcción de objetos (De Micheli, 2001, p. 332).

En 1920 Eisenstein entró a formar parte del Proletkult, y durante los cuatro años siguientes se formó teatralmente a las órdenes de Vsevolod Meyerhold.

De hecho, el interés de Eisenstein por el teatro fue una constante a lo largo de su carrera $\mathrm{y}$, al igual que en el cine, intentó introducir conceptos vanguardistas. Uno de estos data de 1934 cuando junto a Lev Kuleshov ideó un espacio para adiestrar actores, se trataba de "un escenario principal con otros dos que lo flanquean. El escenario principal gira. El espectador se sienta en un disco central que también rota, girándolo hacia el área de acción en el momento adecuado. Las paredes pueden abrirse para mostrar la vista exterior" (Bordwell, 1996, p. 12).

Pasado este tiempo debutó como realizador en el mundo del cine, esa "forma nueva de escribir, y, por lo tanto, de sentir" que diría Bresson (1979, p. 34), con su opera prima: Kinodnevik Glumova (El noticiero de Glumov, 1924), en donde el genio creador de Eisenstein comenzó a aflorar iniciando una búsqueda teórica y práctica que lo acompañó hasta su muerte.

En estos primeros momentos, Eisenstein propuso un nuevo cine afín a la Revolución al que dio el nombre de Cine Dialéctico y que difiere de las teorías de los otros maestros del cine ruso del momento.

Otros dos grandes teóricos de la escena cinematográfica revolucionaria de los que Eisenstein extrajo ideas fueron Dziga Vertov, partidario del Kino Glaz (Cine Ojo) un cine que trata de mostrar la verdad por medio de sus imágenes y que en consecuencia traslada la cámara a la calle donde filma a los "mortales normales filmados en la vida durante sus ocupaciones habituales" (Vertov, 1973, p. 79); y Lev Kuleshov, quien incidió en la importancia del montaje en cuanto forma de expresar la "realidad", la cual puede ser creada y construida con distinta originalidad.

El Cine Dialéctico no tenía tanto la intención de reflejar la realidad como de establecer un juicio ideológico sobre ella. El único sentido de la realidad es el que se le da, la lectura que se hace de ella. Para conseguir este efecto, 
Eisenstein recurrió a un elaborado sistema de montaje cuyo resultado final era un discurso articulado a base de fragmentos cinematográficos. El concepto de fragmento en Eisenstein iba más allá de la unidad mínima que comúnmente se asocia al plano. Para él -dado que usaba planos muy cortos en sus películasesta unidad fílmica estaba más en función de elementos técnicos (luminosidad, contraste, color, duración, etc.) y narrativos (necesaria articulación entre los fragmentos que lo rodean). Estos fragmentos se articulaban según el modelo del conflicto que se produce no solo entre fragmentos sino incluso dentro de ellos, dado que son entidades propias cargadas de significado.

Estas ideas las sistematizó en 1923 en la redacción de su ensayo: Montaje de Atracciones, publicado en el número 3 de la revista $\mathrm{LEF}^{2}$, en el que señaló la gran importancia de producir un choque emocional en el espectador.

La teoría de Eisenstein del choque de imágenes, auténtica agresión a los sentidos, tenía como misión ejercer una influencia directa en el espectador, hacerle participar de la lucha ideológica propuesta por las imágenes, participar, aunque fuera de manera psicológica, de la lucha revolucionaria para alcanzar una "conclusión ideológica final" (Eisenstein, 1923, p. 70-75).

Eisenstein puso en práctica esta teoría del choque emocional en sus primeros films. Así en Stachka (La huelga, 1924) se asiste a una continua referencia de atracciones. Una de las primeras secuencias yuxtapone una serie de planos en los que los informantes de la policía son asociados a los nombres e imágenes de animales traicioneros. Otra secuencia -de gran carácter psicológicomuestra la represión de la masa obrera asociándolo al degüelle de un buey3. Aunque fue en Alexander Nevsky donde esta idea alcanzó su máxima expresión.

En este film perviven las ideas de choque de imágenes para construir en el espectador una determinada toma de conciencia. Así se detectan toda una serie de motivos visuales opuestos. Así, el agua para el bando ruso significaba

\footnotetext{
${ }^{2}$ Acrónimo de Levy Front Iskusstv (Frente de Izquierda de las Artes).

3 Con una función igualmente impactante, Coppola utiliza una secuencia similar al final de Apocalypse Now, su peculiar adaptación de El corazón de las tinieblas de Joseph Conrad.
} 
vida (Alexander y la comunidad que dirige es una sociedad que extrae sus riquezas del lago) mientras que para los germanos el agua era la sepultura final tras la batalla. Atendiendo al vestuario, el de los rusos se asemeja al color de los elementos terrenales, mientras que el de los teutones con el frío y la ausencia de vida. De igual manera, los soldados rusos mostraban en todo momento su rostro en la batalla, mientras que los alemanes usan yelmos que les confiere el aspecto de cubos y seres desprovistos de personalidad.

En este film mostró otro elemento que fue característico de su obra: las masas. Frente al tratamiento estético de Pudovkin, quien pretendía realzar la figura del individuo, Eisenstein hace de la masa un único individuo dramático.

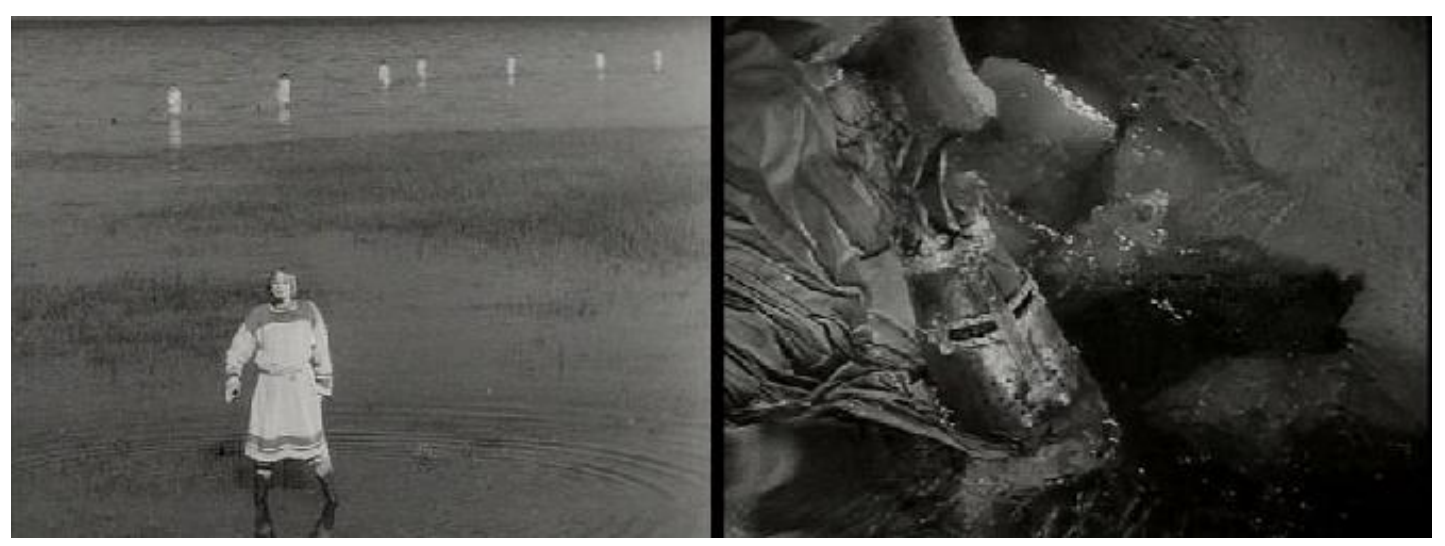

F1. Fotogramas de Alexander Nevsky

Por otro lado, en su cine se apreciaba un gran valor dramático en cada plano. Esta idea es visible en el conocido filme Bronienosiets Potiomkin ( $E l$ acorazado Potemkin, 1925). La sublevación de los marineros del buque insignia de la flota zarista y la tragedia de los que simpatizaron con ellos se convirtió en un auténtico shock visual por medio de primeros planos intercalados vigorosamente: el dolorido cuerpo del marinero azotado, el amargo rictus de Vakulenchuk antes de morir, la crueldad de las botas de los cosacos, las bayonetas pasando por encima de los cuerpos muertos, etc.

La secuencia de la escalinata de Odessa es sin lugar a dudas la que resume la intención del film. Una y otra vez insiste Eisenstein en las atracciones: la inminencia del ataque a los marineros se resalta por planos de máquinas paradas; la muerte del médico -representante de la opresión zarista- se acentúa con un plano de las lentes colgando por la borda. Entre todo el caos 
que se genera en la represión y la huida por la escalinata "la multitud es individualizada por medio de grandes rostros o por detalles de actitudes y vestimentas, escogidos con un sentido inigualable de caracterización [...] el episodio, por otro lado, está puntuado por atracciones violentas y desgarrantes: la madre con el cadáver del hijo en los brazos, el carro de la criatura, abandonado, rodando por la escalera, el ojo vaciado sangrando por detrás de los lentes quebrados" (Sadoul, 1967, p. 137)

Junto al significado político, Eisenstein utilizó en este film una serie de motivos que entroncan con la tradición artística, iconos a los que reviste de una lectura diferente, netamente ideológica.

Una de las secuencias más cargadas de significado ideológico muestra a un marinero en actitud pensativa mientras lava la vajilla de los oficiales. Eisenstein construye esta secuencia por medio de primeros planos del marinero y planos detalle de la cubertería de plata, los lujosos platos, etc. El choque se produce cuando el marinero lava un plato que tiene escrito en su borde las palabras del Padrenuestro: "Danos el pan nuestro" cuya lectura produce un efecto de concentración y reflexión que deriva en la toma de decisión de amotinarse. El discurso para el público sería: la revolución -la liberación de la tiranía zarista y sus sostenedores- pasa por una toma de conciencia previa.

Como señala Balló (2000, p. 111) la escalera "supone una estructura de poder y contrapoder, de opresión y rebelión [...] señala la distancia entre la masa y los elegidos, como se manifiesta en la mayoría de las películas basadas en la visualización del poder imperial". En la secuencia de la escalinata las subidas y bajadas remarcan el enfrentamiento -la lucha de conceptos antagonistasentre opresores anónimos de los que tan solo se ve el rítmico descenso de las botas - de nuevo icono asociado al poder- y víctimas individualizadas. Todo ello presentado por una cámara bien con angulación enfatizada bien usando un vertiginoso travelling de retroceso. Tampoco es casual la disposición de los grupos de individuos en la secuencia: en la parte superior la fuerza represora gubernamental; en la inferior: la masa reivindicativa que a la postre es masacrada. 
El referente icónico de la Piedad tiene unas marcadas connotaciones religiosas, que en manos de Eisenstein sufre una desacralización que no le hace perder el dramatismo, aún más, acaba por reforzarlo. El motivo en sí es la secuencia de la madre con el niño muerto en brazos que asciende la escalinata para enfrentarse a los verdugos. El realizador rompe así con la tradicional pietá estática y resignada para dotarla de actividad y dinamismo: es parte del proceso de toma de conciencia frente a la opresión, una lucha contra el conformismo establecido por la concepción ortodoxa del cristianismo.

Una nueva producción cinematográfica de Eisenstein tuvo lugar en 1927, año en el que se conmemoraba el décimo aniversario de la Revolución. En esa fecha filmó Oktiabr (Octubre, 1927) película en la que adaptó la obra de John Reed Diez días que conmovieron al mundo. La idea teórica de la que partió es la del Cine de Masas, una concepción cinematográfica de nuevo cuño que trataba de crear un cine pedagógico, que fuera un material didáctico que ayudará a consolidar la conciencia revolucionaria del espectador. La manera más sencilla de conseguir este propósito es mediante la realización de películas de género histórico.

Oktiabr, integraba dos géneros diametralmente opuestos: documental y ficción. La vertiente documental se encuentra en la localización exacta en donde ocurrieron los acontecimientos, los objetos reales asociados a los personajes e incluso en el uso de imágenes documentales -strictu senso- de algunos de los protagonistas.

El discurso didáctico del film muestra la necesidad de acabar con el dominio de los Romanov, la ineficacia del gobierno provisional de carácter burgués de los mencheviques liderados por Kerenski y la necesaria toma del poder por parte de los bolcheviques -el revolucionario del pueblo, el pueblo mismoúnica fuerza capaz de imponer orden en el proceso revolucionario.

Para argumentar todo ello recurrió a imágenes de choque, como las secuencias que asocian las imágenes de los Romanov con los iconos rusos; o la secuencia en la que muestra a Kerenski ascendiendo lentamente la escalera -de nuevo asociada al poder- del Palacio de Invierno, a la que contrapone la figura de un pavo real mecánico: símbolo de la vanidad. Todo ello lo hizo por medio de un 
montaje transmisor de sentidos connotados, es decir, usando planos en los que relaciona "dos elementos diferentes para producir un efecto de causalidad, de paralelismos, de comparación” (Aumont, 1985, p. 68).

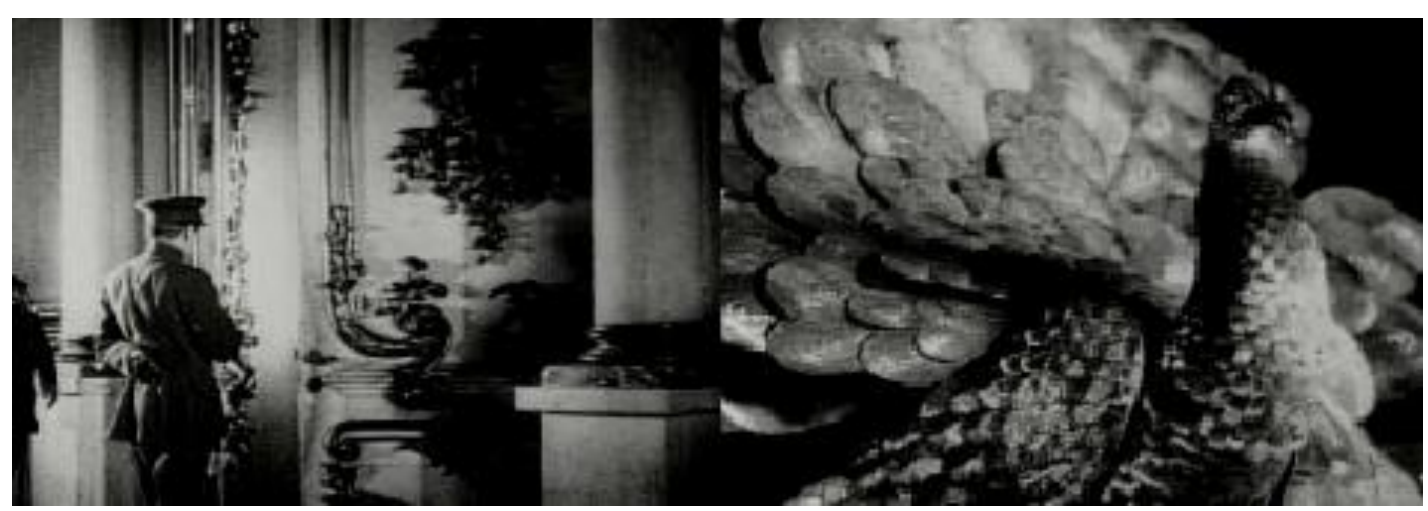

F2. Fotogramas de Octubre

\section{El Realismo Socialista y el cine de Eisenstein}

La libertad creativa que se vivió en la Rusia revolucionaria, sufrió un brusco viraje en 1928 con la entrada de la Nueva Política Económica implantada por Stalin. En este momento, los sectores artísticos y culturales ligados a la burocracia stalinista iniciaron un proceso de homogeneización y depuración de la vida artística. En abril de 1932, el Comité Central hizo público el decreto Sobre la reorganización de los grupos literarios y artísticos que en esencia supone la disolución de las corrientes artísticas ligadas a la vanguardia, y el giro a una creación artística oficial ligada a las necesidades ideológicas del Estado y del sector stalinista, es el llamado realismo socialista.

Este nuevo arte obligó a los artistas a presentar una serie de temas estereotipados como son la realidad en su vertiente revolucionaria, los personajes y situaciones típicas, los medios sociales, los héroes constructores de la sociedad socialista y en especial a Stalin y los acólitos de su corte de poder desde una perspectiva denominada realismo heroico.

Zdhanov, organizador de la cultura oficial tras la caída en desgracia de Lunatcharsky, describe el realismo socialista como sigue: 
Tout d'abord, cela signifie qu'ils doivent connaitre la vie pour la représenter fidèlement (...) non comme un objet mort, même pas comme une réalité objective, mais pour représenter la réalité dans sa dynamique révolutionnaire. Ensuite, conformément à l'esprit du socialisme, ils doivent combiner la fidélité et la représentation artistique historiquement concrète avec le travail de modélisation idéologique et d'éducation des travailleurs (Golomostock, 1991, p. $45) \cdot 4$

La entrada en escena de esta nueva cultura politizada y dirigida por el Estado, supuso la prohibición de obras de pintores vanguardistas como Malevich, Filonov y Lebedev, de escenógrafos como Meyerhold cuyas obras fueron tildadas -desde las páginas de Pravda-de burguesas y reaccionarias.

No obstante, otros artistas, como Prokofiev, se convirtieron en defensores acérrimos del compromiso del artista con el momento social e histórico que atravesaba Rusia. En definitiva, el realismo socialista impuso una visión monolítica de la cultura, rasgo que caracteriza a todas las manifestaciones del arte totalitario

El cine, como manifestación artística, no escapó a la nueva coyuntura cultural que se impuso en la Rusia Soviética, pues no en vano, el mismo Stalin manifestó que "el cine ayuda a la clase obrera y a su partido a educar a sus trabajadores en el espíritu del socialismo, a organizar a las masas para la lucha por el socialismo, a elevar su nivel de cultura y su capacidad de lucha política” (Katayev, 1938, p. 3).

El cine del realismo socialista estuvo marcado y vigilado por los intereses del propio Estado, quien privilegia dos temas básicos en toda la producción: la exaltación del héroe individualizado y positivo y el canto hacia la máquina como símbolo del desarrollo industrial.

La exaltación del héroe adquirirá un carácter didáctico, puesto que se convertía en un ejemplo a seguir, un modelo de conducta. Eligiendo estos

\footnotetext{
4 En primer lugar, significa que deben conocer la vida para representarla fielmente (...) no como un objeto muerto, ni siquiera como una realidad objetiva, sino para representar la realidad en su dinámica revolucionaria. Entonces, de acuerdo con el espíritu del socialismo, deben combinar la fidelidad y la representación artística históricamente concreta con el trabajo de modelado ideológico y educación obrera.
} 
modelos en épocas remotas de Rusia, con especial predilección por la Edad Media, surgieron así en la producción cinematográfica una peculiar panoplia de líderes "llenos de energía, con una visión progresista que anticipaba la victoria del socialismo" (Bordwell, 1999, p. 239). Curiosamente, las figuras representadas como exponente de estas ideas eran caudillos y reyes presentados como "progresistas", en la línea propuesta tanto por Stalin como por la historiografía surgida bajo su mandato que en definitiva no hacía más que apuntar hacia la personalidad de Stalin como el líder indiscutible.

El propio Eisenstein se mostró incondicional del nuevo concepto de arte desde 1934, fecha en la que comenzó a publicar una serie de artículos en los que defendía la nueva estética ligada al poder, pero -influenciado por Lenin- sin perder de vista la tradición cultural anterior a la revolución que puede ser utilizada en la consecución de un arte total e innovador, en sus propias palabras:

Nuestro realismo, el realismo del futuro, tiene que incorporar todas las viejas artes. Pero éstas no bastan por sí solas. Esto no sólo es socialismo sino el método completo de la creación artística. En la obra de creación que hagamos, podemos utilizar toda la experiencia de la humanidad a lo largo de la historia (Bordwell, p. 196).

En sus escritos, Eisenstein prestó una gran atención a la relación del cine con otras manifestaciones artísticas, especialmente la pintura de la que tomará constantes referencias. En concreto, en Iván el Terrible se puede observar una clara referencia a los personajes pintados por El Greco, pintor por el que el cineasta ruso manifestó una especial predilección pues bien se puede observar el tratamiento formal que otorga Eisenstein a los personajes, y en especial al zar Iván: rostros de pómulos marcados por la incidencia de la luz, miradas penetrantes, fondos neutros, etc.

\subsection{Alexander Nevski: el contrapunto audiovisual}

La ilustración de los arquetipos de la sociedad postrevolucionaria los ilustró con dos figuras tomadas del pasado ruso: Alexander Nevski e Iván IV. 
Aleksandr Nevski (1938) tenía, de nuevo, una intencionalidad didáctica, en esta ocasión de carácter anticipatorio: el constante peligro del expansionismo alemán reflejado en el film por medio de la Orden Teutónica. En un contexto histórico en el que las naciones europeas utilizaban el cine con claras intenciones políticas, Stalin auspició en la URSS una producción acorde con esta coyuntura, fruto de la cual es la vuelta de Eisenstein a la pantalla por medio de Alexander Nevski, película que reflejaba la gesta épica del héroe de Novgorod que derrotó a los Caballeros Teutones. No obstante, la censura stalinista se cebó en esta obra ya que en 1939 -y para sorpresa de las naciones europeas- Alemania y la URSS firmaron un acuerdo de no agresión, que demostró su solidez, provisionalmente, en la invasión y reparto de Polonia por parte de las dos naciones. Junto a esta advertencia del peligro alemán, Eisenstein propugnaba la necesidad de encontrar un líder - un jefe militarque fuera capaz de frenar ese avance imperialista. La figura -bolchevizadade Alexander Nevski aunaba en torno a sí a todas las capas sociales del pueblo ruso: nobles, comerciantes, artesanos, campesinos, etc., trascendiendo así la figura personal para revestirse de un carácter más sublime: el de la patria misma.

Desde finales de los años 30, Eisenstein había teorizado acerca del contrapunto audiovisual, expresión bajo la que englobaba la suma de todos los elementos que constituyen la imagen fílmica y el sonido. Según esta teoría "los diversos elementos sonoros, palabras, ruidos, música, participan en igualdad con la imagen, y de modo bastante autónomo respecto a ella y a la constitución del sentido: pueden reforzarlo, contradecirlo o, simplemente, tener un discurso paralelo" (Aumont, p. 85). La teoría se revelaba realmente globalizadora e integradora del audiovisual.

Para Eisenstein una película tiene momentos fuertes y débiles, cada plano posee un acento que se corresponde con su equivalente musical y es el realizador quien "coordina el ritmo de la banda sonora [...] con el ritmo del contenido interno y duración de los planos" (Bordwell, 1999, p. 218). Estas correspondencias adquieren el carácter de verticalidad en el momento en que 
"relacionan la música con las tomas merced a un movimiento idéntico que es la base de los movimientos musical y pictórico” (Eisenstein, 1999, p. 127).

Eisenstein dota la narración de esta película de una rapidez, precisión y agudeza hasta el momento nunca vista, consiguió una estructura audiovisual que roza la perfección. En efecto, la novedad del film lo supone la incorporación de la banda sonora, esto es: la conjunción de música, ruidos y diálogos.

Los diálogos de Palenko y Eisenstein y la música de Prokofiev se funden en lo que el maestro ruso había desarrollado en la teoría del contrapunto audiovisual como él mismo explicaba:

Deseo destacar que en Alexander Nevski se emplearon literalmente todos los métodos posibles. Hay secuencias en las que las tomas se recortaron para ajustarlas a un curso musical previamente grabado. En otras la música entera fue escrita para el encuadre definitivo de la película. Algunas contienen ambos métodos [...] De la misma manera, pero a la inversa, algunos pasajes de la partitura sugirieron soluciones visuales plásticas que ni Prokofiev ni yo habíamos previsto. A menudo se adaptaban tan perfectamente al sonido interior unificado de la secuencia, que ahora parecen concebidas así de antemano (Esisenstein, 1999, pp. 115-116).

Pero el enfrentamiento no solo se produce a nivel visual, en esta película Eisenstein experimenta con el choque sonoro. En efecto, la música "se encarga, aunque de una manera más local y más episódica, tanto de describir como de expresar" (Aumont-Marie, 1999, p. 209).

Esta capacidad narrativa de la música se encuentra a lo largo de todo el film. El primer caso es la canción que acompaña a los planos iniciales del film y que recuerda la victoria de Alexander sobre los suecos. En la secuencia en la cual Alexander es elegido caudillo y dirige el levantamiento de Novgorod, la música que se oye es "En pie, pueblo de Rusia”, similar es el caso del coro femenino que se deja oír entonando “iLevántate, Rusia, nuestra madre!” mientras que Olga se viste la armadura. También Eisenstein y Prokofiev construyen una contraposición entre los motivos sonoros que identifican a los Teutones y a los rusos. Así, los primeros están dominados por la presencia de himnos católicos 
interpretados por un -siniestro- monje; mientras que en el bando ruso predominan melodías de carácter popular, composiciones por las que Prokofiev había demostrado un especial interés desde mediados de los años 30.

Desde la apreciación visual, la estructura compositiva de esta secuencia se construye por medio de un montaje analítico en el que fragmenta la realidad en una relación de planos próximos y de escasa duración, de manera que el paso de un encuadre a otro produce de por sí una tensión emocional. Esta sensación de contenido dramático se acrecienta aún más con la confrontación de líneas horizontales (el avance teutón) y verticales (el muro de lanzas rusas) siendo siempre estos últimos elementos los que van a dominar y al final salir vencedores del conflicto.

Esa tensión, la espera ante el avance de los invasores, es acentuada con un movimiento visual ascendente y descendente en arcos que súbitamente caen sobre una horizontal que viene a simbolizar la incertidumbre.

En la secuencia de la batalla se asiste, por otro lado, a una perfecta armonía entre los diferentes planos fotográficos y los compases musicales que remarcan el protagonismo de los personajes rusos: los únicos que hablan, los que manifiestan -exaltados o con indiferencia- la dimensión humana de la contienda; el contraste son los caballeros teutones a los que Eisenstein priva de personalidad al mostrarlos de manera recurrente ocultos tras sus yelmos.

Eisenstein agrupa los planos de manera que se correspondan con las frases musicales, alternando los planos generales con los primeros planos. Establece al mismo tiempo un ritmo visual en continuos ascensos y descensos -una especie de arco de tensión-, en los que la carga visual estará repartida hacia los extremos, y que son interrumpidos por planos generales de marcada horizontalidad. El efecto que consigue crear con esta disposición de las imágenes y de la música es el de anticipación de la tensión, es decir: en los planos que construyen el arco y que coinciden con una melodía ascendente marcan la tensión, se trata tanto de los planos generales en los que aparecen las figuras en la cumbre como los primeros planos de los guerreros rusos. 
Por otro lado, crea un efecto de calma al introducir una serie de planos generales construidos por la horizontal del ejército ruso y el nevado paisaje tras el cual se encuentra la amenaza, la correspondencia musical es una melodía que remarca esta sensación de espera.

Pero el uso del sonido no queda relegado únicamente a la música, al mismo tiempo que ésta se convierte en constructora del dramatismo, los sonidos naturales emanados de la acción se revelan de gran importancia. En este sentido y dentro de la secuencia de la batalla, Eisenstein introduce la importancia del sonido en momentos decisivos. Así tras la repetitiva música que acompaña al avance de la caballería alemana y que va acelerándose conforme se encuentran más cerca de los rusos, se interrumpe súbitamente en el momento en el que las dos fuerzas militares chocan, privilegiando así el ruido natural de las armas. Algo similar ocurre en el ataque en tenaza de los rusos que cercan a los teutones cuando de nuevo la música se interrumpe y se oye el sonido del combate y con la muerte de uno de los caballeros alemanes vuelve la música a la pantalla con la interpretación de un tema victorioso.

\subsection{Ivan el Terrible: el sonido del color}

Alexander Nevsky supuso la primera realización de Eisenstein con la que pudo comenzar a experimentar con el sonido. Tras esta producción, la serie de Ivan Grozny (Iván el Terrible, 1944 - 1948) continuó el camino iniciado en el uso del sonido, y aún más en la incorporación del color, un recurso para el que tenía en mente toda una nueva teoría.

Acorde con los principios del realismo socialista no es de extrañar que Eisenstein manifestara su interés por centrarse en Iván IV, el "zar que enriqueció y fortaleció la posición económica de Rusia” (Eisenstein, 1982, pp. 26-27), al que va a abordar desde una perspectiva épica que le sirve para ilustrar la idea del líder absoluto que se convierte en personificación del pueblo.

Concebida como trilogía, finalmente la realización de Iván el Terrible quedó reducida a las dos primeras partes filmadas en el largo periodo de 1944 a 1946 
en Kazajstán, lugar al que se habían trasladado los estudios cinematográficos tras el estallido de la guerra contra Alemania.

El proyecto de Eisenstein era mostrar al zar Iván como un exponente del progresismo que además se ayuda de una guardia de corps -la Oprichninapara hacer realidad sus proyectos. Para construir esa imagen presenta a Iván como un ser atormentado, en ocasiones rayando la esquizofrenia, y en constante lucha contra los enemigos interiores y exteriores para salvaguardar el poder. En definitiva, aparece como "el único líder fiable, enclaustrado por las exigencias de la vida pública, por la privación personal y sobresaliendo por la soledad del liderazgo, recurriendo a sus recursos y a los de los demás para cumplir con la tarea que, según él, la historia le ha puesto ante sí” (Bordwell, 1999, p. 260).

Puesto que el componente psicológico está presente a lo largo de todo el film, Eisenstein recurrió a una puesta en escena que remarcaba estos elementos. Así los decorados se revelaban expresionistas con líneas quebradas, dominados por las sombras y por las arquitecturas que engullen a los actores; la actuación hierática muestra el interior de los personajes: sus pensamientos y emociones. Al mismo tiempo se sirvió de recursos técnicos para construir ese ambiente opresivo siendo el más espectacular el uso de la profundidad de campo por medio del empleo de un objetivo de gran angular que permite colocar la figura en gran primer plano, muy cerca de la cámara, y tener una perspectiva muy nítida de lo que acontecía al fondo del encuadre, como en la toma del pueblo de Moscú que acude en procesión para rogar a Iván que vuelva a la capital. Más impactante es este tipo de encuadre en las escenas de interior en las que personajes y objetos, junto a este uso focal, hacen del escenario un lugar claustrofóbico no solo para los personajes sino incluso para los espectadores que son introducidos por el realizador en el peculiar mundo de Iván: un mundo de intrigas, conspiraciones y falsas lealtades.

Lo cierto es que las imágenes establecían cierto paralelismo entre los personajes históricos y los actuales: Iván y Stalin, Malyuta y Beria, la Oprichnina y la cohorte de acólitos de Stalin. Similitudes que no pasaron 
desapercibidas y motivaron la prohibición de la segunda parte de la película por orden del Comité Central.

Por otro lado, la puesta en escena de la película revelaba una influencia directa del teatro Kabuki, del cual Eisenstein se había mostrado un incondicional desde que en 1929 asistiera a una representación de este género teatral japonés. El realizador quedó impactado con la estética Kabuki y señaló que esta sería la manera que debía adoptar el cine sonoro puesto que en estas representaciones teatrales "sonido, movimiento, espacio, voz no se acompañan (ni siquiera en paralelo), sino que funcionan como elementos de igual importancia” (Eisenstein, 1986, p. 26).

A grandes rasgos, la influencia "japonesa" en Eisenstein se hace evidente en rasgos como la apariencia de los actores gracias al uso de un determinado atrezzo y, por otro, el protagonismo de la música.

En el Kabuki es fundamental el uso de máscaras para caracterizar a los actores, Eisenstein retoma esta idea y lo lleva a la pantalla por la propia caracterización, interpretación y filmación de los actores, resultando que "les acteurs aux visages aigüs deviennent principalement des actants, et les acteurs aux visages ronds sont de nature plus passive et subordonnée"5 (Dumas, 2010). En otras ocasiones la referencia es más directa aún, como en la secuencia del baile de la Oprichnina donde Fiodor aparece en escena ataviado con ropas que recuerdan a la zarina Anastasia y ocultándose tras una máscara blanca.

Las posibilidades de conjugar música, danza e interpretación lo que más atrae a Eisenstein ya que la base del kabuki reside en la conjunción de diálogos con partes entonadas e intermedios de ballet, consiguiendo el efecto que él mismo señala: “oímos el movimiento y vemos el sonido” (Eisenstein, 1986, p. 31) y que ya había puesto en práctica en Alexander Nevsky.

Eisenstein había tomado influencias de pintores y artistas de épocas clásicas. Pero las referencias pictóricas irán más lejos, pues Eisenstein -desde finales de los años 30- empieza a mostrar interés por los artistas que teorizan sobre

${ }^{5}$ Los actores con caras alargadas se vuelven principalmente activos, y los actores con caras redondas son de naturaleza más pasiva y subordinada. 
las relaciones entre pintura y música. Este tema es de interés ya que en la secuencia del banquete de la Oprichnina Eisenstein pone en escena todo un despliegue de imágenes dominadas por tres colores: rojo, dorado (variante del amarillo) y negro.

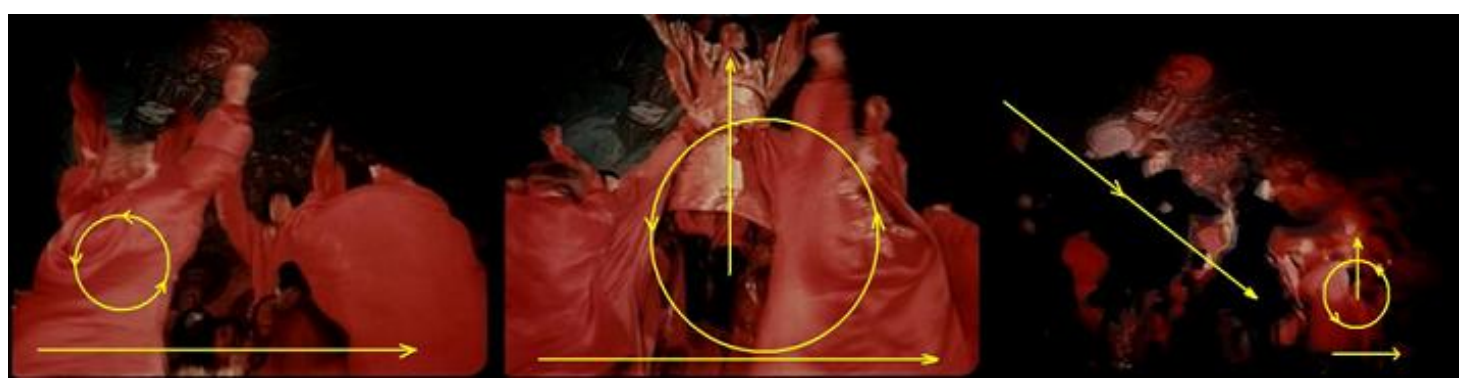

F3. Esquema de movimientos en Iván el Terrible

Emplear estos colores se explica por la carga simbólica que el realizador encuentra en cada uno de ellos, para lo que recurre a las teorías de artistas y pintores de la tradición cultural de finales del XIX.

Eisenstein reconoce el lenguaje de los colores refiriéndose a ellos como poseedores de una tonalidad interior que deben "contribuir al significado de un sentimiento interior (...) que halla expresión exterior en colores, líneas y formas" al mismo tiempo que los "colores ejercen influencias específicas en el espectador" (Kandinsky, 2001, p. 54).

Una vez establecida esta premisa, el cineasta comenzó a delimitar los colores que considera básicos y a los que dotará de un significado concreto, a saber:

a) Dorado (amarillo): Recurriendo a la tradición pictórica, Eisenstein retoma el simbolismo asociado a la traición, la discordia (Eisenstein, 1999, p. 91). Coincidiendo con Kandinsky en la faceta negativa que posee el color: "El amarillo contemplado directamente (...) inquieta al espectador, le molesta y le excita y descubre el matiz de violencia expresado en el color, que actúa descarada e insistentemente sobre su sensibilidad" (Kandinsky, 2001, p. 73).

b) Rojo: En el caso de este color Eisenstein también coincide de nuevo en las teorías expuestas por Kandinsky quien señala que este color "da la sensación de fuerza, energía, impulso, decisión, alegría, triunfo" 
(Kandinsky, 2001, p. 79), al tiempo que también señala que este color recuerda el sonido de los metales de la orquesta.

c) Negro: En cuanto al negro, el significado que le otorga Eisenstein no puede ser menos amenazador, ya que, como recuerda Kandinsky, el negro es el "color de la más profunda tristeza y símbolo de la muerte" (Kandinsky, 2001, p. 78).

De igual manera que sucediera en Alexander Nevsky el realizador concede una importancia capital a la conjunción de la música y las imágenes según su teoría del montaje contrapuntístico, la perfecta unión de planos y temas musicales según un ritmo marcado por el movimiento intrínseco de cada plano, e incluyendo la conexión con los colores que se impone en cada plano. Esta idea la materializa haciendo coincidir el ritmo de la banda sonora, en especial de la música, con el contenido y duración del plano.

Eisenstein encarga una partitura a su habitual colaborador: Prokofiev. La importancia que Eisenstein otorgaba a la música era tal que el mismo Prokofiev la señala con estas palabras: "Eisenstein tenía tanto respeto por la música que a veces estaba dispuesto a reducir o prolongar secuencias para no perturbar el equilibrio del episodio musical" (Bordwell, 1999, p. 256).

De manera específica le indicó que la composición debía tener características wagnerianas con la presencia de un motivo continuo (leitmotiv) que pudiera insertar a lo largo del film, influencia nada extraña si se tiene presente que el director había hecho un montaje de la ópera Die Walküre en 1941. Pero dicho acompañamiento musical presentará de nuevo similitudes con las teorías expuestas por Kandinsky en cuanto a significado del color y tonalidad del mismo, tal y como se expone en el siguiente cuadro:

\begin{tabular}{|l|l|l|l|l|}
\hline \multirow{2}{*}{ Colores } & \multicolumn{2}{|c|}{ Significado } & \multicolumn{2}{c|}{ Tonalidad } \\
\cline { 2 - 5 } & Kandinsky & Eisenstein & Kandinsky & Eisenstein \\
\hline Dorado & Discordia & Traición & Estridente & Cuerdas \\
\hline Rojo & Fuerza & Poder & Metales & Viento/Metales \\
\hline Negro & Muerte & Venganza & Pausa & Percusión \\
\hline
\end{tabular}


Una serie de motivos sonoros acompañan las diferentes acciones de la película. Así se pueden identificar dos temas principales: una potente fanfarria relacionada con la lucha por el poder encabezada por Iván; seguida de una melodía que se aplica cuando se reflexiona sobre el destino de Rusia.

A los que se unen otros de menor presencia, pero no protagonismo, como son: la canción de cuna que entona Efrosinia para calmar a su hijo Vladimir, el baile de la Oprichnina en la que simbólicamente se está presentando las intrigas y luchas por el trono, o la mazurca que acompaña la traición de Kurbsky al rendir homenaje al rey polaco.

En definitiva, en el caso de Iván el Terrible la música tiene un protagonismo en igualdad de condiciones que la imagen, al punto de que en ocasiones los primeros acordes que irrumpen en el plano ya están anunciando los acontecimientos que los personajes van a interpretar.

La puesta en práctica de las ideas referidas al color y a la música se sistematiza sobre la pantalla en la escena del baile de la Oprichnina, la primera secuencia en color que filma Eisenstein -y que está llena de sugerencias y lecturas- se caracteriza por la interrelación de cuatro colores que encuentran igualmente su correspondencia musical.

Toda la secuencia se organizó acorde a la música que Prokofiev había grabado con anterioridad, de manera que Eisenstein hace coincidir el movimiento de los danzantes con los acentos musicales, y será precisamente la estructura musical la que marcará la transición del color dominante en cada encuadre y el cambio de plano, estando presente en todo momento la idea del leitmotiv, de la repetición insistente -por medios visuales y sonoros- de una idea: el castigo a la conspiración contra el Zar.

La estructura de la escena puede sintetizarse en una serie de frases audiovisuales.

\subsubsection{Primera parte musical}

Se inicia con una melodía que es el leitmotiv y que se escucha de manera recurrente asociado a los planes de Iván: la eliminación de los boyardos. En el 
tema musical predominan los sonidos del metal y viento, en plena coincidencia con la tonalidad roja y dorada de los bailarines.

De igual manera la repetitiva música acompaña los planos en los que hay un desplazamiento de los bailarines en tres diferentes movimientos: horizontal, símbolo de las infinitas posibilidades del poder, y circular excéntrico marcado por el color rojo en ambos casos y por uno de los bailarines, con indumentaria dorada, que con movimiento ascendente y descendente significa la búsqueda del poder por parte de los boyardos. La irrupción en el encuadre de la Oprichnina vestida de negro con un movimiento en diagonal que se interpone en la acción de los planos anteriores (que aún se percibe gracias a la profundidad de campo en un segundo plano) se corresponde con el inicio de la percusión que secciona la melodía principal en diferentes momentos asociados siempre a la Oprichnina, y que alcanza su máxima expresión por la atenuación de la música y el protagonismo de la percusión efectuada por las botas de estos últimos danzantes. Precisamente las botas serán un motivo iconográfico al que Eisenstein recurre insistentemente en sus películas asociándolo al carácter opresivo del poder.

El tránsito del rojo y del amarillo al negro están bien fundamentados en la teoría del color de Kandinsky quien manifiesta en una de sus antinomias que el movimiento excéntrico del amarillo llegará a alcanzar el color negro. En la práctica musical de la banda sonora, la impetuosa melodía que da inicio a la secuencia es llevada al dominio absoluto del ritmo del taconeo de la Oprichnina anunciando el castigo a quien trata de alcanzar el trono.

\begin{tabular}{|l|l|l|l|l|}
\hline \multirow{2}{*}{ Movimiento } & \multicolumn{2}{|c|}{ Concéntrico } & \multicolumn{2}{c|}{ Significado } \\
\cline { 2 - 5 } & Kandinsky & Eisenstein & Kandinsky & Eisenstein \\
\hline $\begin{array}{l}\text { Amarillo / } \\
\text { dorado }\end{array}$ & Rojo & Rojo & Movilidad & Conspiración \\
\hline Rojo & Azul & Negro & & Poder \\
\hline Negro & Negro & & Inmovilidad & Venganza \\
\hline
\end{tabular}


Similar esquema se repite con la entrada de Fiodor en escena, ataviado de manera que recuerda a Anastasia (referencia a los papeles femeninos interpretados por actores masculinos en el kabuki), la zarina asesinada, antes de interpretar una canción alusiva a la conspiración de los boyardos.

La entrada de Fiodor desde el lateral izquierdo del encuadre establece una diagonal con respecto a la recargada horizontal formada por los hombres de la Oprichnina. Además, su aparición se acompaña por instrumentos de viento, marcando así una transición dentro del ritmo asociado a cada una de las apariciones de la Oprichnina. Tras la danza que efectúa Fiodor -y unos planos de Iván- entran en escena una serie de bailarines que mantienen el esquema rojo dorado siendo acompañados por la música sinfónica del principio. El movimiento circular concéntrico, ya que hay diferentes formaciones circulares de bailarines, están remitiendo de nuevo a la tensión interior de los boyardos por alcanzar el poder. Acorde con la estructura que Eisenstein ideara, de nuevo es el color negro el que acabará adueñándose de la escena, imponiendo de nuevo el ritmo sobre la melodía, en este caso con palmadas. De igual manera, la ruptura con la acción de los planos anteriores es señalada por el movimiento diagonal que efectúan los danzantes -una ruptura con el baile circular precedente y que al ser filmado desde un punto de vista frontal remarca la horizontalidad del mismo- en un primer momento $(1-2)$ alejándose de la acción para luego (3-4) acercarse de nuevo sobre la escena que se desarrolla, presentando de nuevo la opresión del poder de Iván y su guardia de corps.

Este mismo esquema se repite -con una aparición a la inversa de los colorescon la escena de los bailarines saltando sobre la escalera y agrupándose en el suelo en un maremagnun de rojo y oro, como un macabro anuncio de lo que sucederá con los boyardos.

\subsubsection{El diálogo entre Iván, Vladimir, Basmanov y Malyuta}

Tras las imágenes anteriores, Eisenstein efectúa una aproximación a la misma idea que organiza la primera parte musical por medio del diálogo con sus más cercanos colaboradores. 
En correspondencia con la parte musical, el protagonismo del color es notorio, ya que Basmanov -jefe de la Oprichnina- viste de negro y en correspondencia con la tensión y el ritmo de la percusión de los bailarines, en el dialogo con él hay una marcada tensión debido a que cuestiona los medios de acción del Zar.

No obstante, destaca la composición formal que adoptan los personajes de Iván y Vladimir en un triángulo que muestra la realidad del poder del Zar. Vladimir es el candidato elegido por los conspiradores boyardos para ser elevado al trono. El carácter usurpador y traidor de esta pretensión es puesto en escena por Eisenstein otorgándole al protagonista una vestimenta dorada (amarilla) tonalidad que el mismo reconoce estar asociada con la traición desde época muy remota. Por contraposición, Iván, que aparece en un plano superior está vestido de rojo: color dinámico, vital y asociado al poder exaltado.

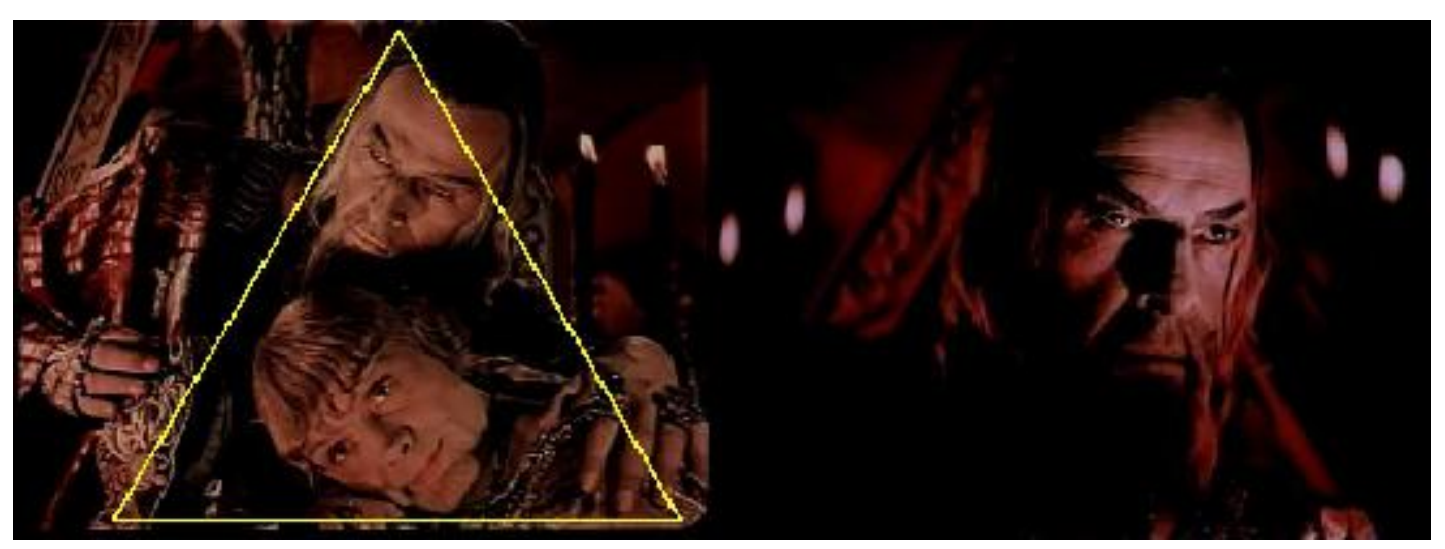

F4. Composición visual en Ivan el Terrible

Pero Eisenstein otorga además otra lectura al rojo al retomar ideas que están presentes en trabajos psicológicos y recuerda que este color tiene una conexión con patologías de la mente y en especial con la histeria, ya que, haciendo referencia a los trabajos del psiquiatra Havelock Ellis, Eisenstein menciona: “esta persistencia de la visión del rojo por los histéricos es sólo un ejemplo de la predilección por el rojo que se ha observado como muy frecuente y marcada entre tales enfermos" (p. 107).

Durante las dos partes de la película Iván aparece como un ser dominado por sus pasiones y sus miedos a la hora de actuar, y en más de una ocasión 
demuestra estar dominado por un nerviosismo patológico a la hora de tomar determinadas decisiones.

La culminación de esta parte no puede ser más perfecta. Iván busca con la mirada a Fiodor, que observa desde las sombras la conversación del Zar. Eisenstein establece así no solo un raccord visual con el eje de las miradas de los personajes, sino además una continuidad en la narración ya que la vestimenta de Fiodor se corresponde en tonalidad con la de Vladimir, empezando de esta manera la segunda parte musical -en la que se escuchan los acordes del leitmotiv a manera de introducción- donde se anuncia por medio de una canción las intrigas que han llevado a cabo los boyardos y cómo van a recibir el castigo de Iván.

\subsubsection{Segunda parte musical}

Todo el tema cantado es, de nuevo, un anuncio del mismo tema que es escenificado al unísono entre Fiodor y los bailarines de la Oprichnina. En los planos finales de la secuencia se aprecia la idea en todo su esplendor: Fiodor rodeado por los demás salta frenéticamente arriba y abajo mientras todos agitan sus brazos y el coro emite un onomatopéyico “iSchip! iSchip” al tiempo que los destellos de dorados y rojos remiten al trabajo del hacha -a la que se alude insistentemente en la canción- cortando los cuellos de los traidores. El mismo Eisenstein (p. 94) se inspiraba en el poema "Chispas emergidas de la rueda" de Walt Whitman para ilustrar sus ideas acerca del color amarillo: "Contra el borde de la acera, donde terminan las losas, / un afilador, con un cuchillo entre las manos, / inclinado sobre la piedra, aplica atentamente el acero contra ella, / en tanto con el pie y la rodilla, / la hace girar rápidamente, con un movimiento igual, / mientras se desprenden, en abundante lluvia de oro, / las chispas que brotan de la rueda". Curiosamente este mismo poema es fuente de inspiración para el cuadro Malevich: "Afilador de cuchillos".

Terminada la canción se vuelve a escuchar el tema principal que acompañó a la primera parte, coincidiendo de nuevo con la secuencia de colores rojo, dorado y negro; hasta concluir con una configuración de los personajes formando una pirámide -con Fiodor en la cúspide- que coincide con la fanfarria asociada por el realizador a la máxima expresión de poder. 


\section{Conclusión}

Como se ha expuesto, Eisenstein otorgó una importancia capital a las relaciones ideológicas y estéticas a sus obras. Desde sus inicios en el mundo teatral hasta sus últimos escritos supo identificar el valor de impacto que tanto imagen como sonido tienen en el espectador a la hora de percibir y comprender una idea.

Las funciones dramáticas y simbólicas que había otorgado a los planos de Bronienosiets Potiomkin (El acorazado Potemkin, 1925) han trascendido a otros realizadores y se han homenajeado en filmes posteriores de diversos géneros como el thriller Godfather (El padrino, Francis Ford Coppola, 1972), el policiaco The Untouchables (Los intocables de Elliot Ness, Brian de Palma, 1987) o la distopía totalitaria Brazil (Brasil, Terry Gilliam, 1985). La dialéctica propuesta en los mundos representados en Aleksandr Nevski (1938), la naturaleza como símbolo de vida y triunfo del bien, frente a lo artificial como símbolo de la destrucción y el mal, se puede rastrear en la saga Star Wars (1977 - 2015) en los dos bandos enfrentados: la Rebelión, asociada a espacios naturales, frente al Imperio, representados como tecnificados y carentes de humanidad.

No menos importante es el empleo que Eisenstein otorgó al empleo del sonido y el color. Su fallecimiento le impidió concluir la teoría que estaba concluyendo sobre el empleo en igualdad de importancia. No obstante, en la secuencia en color de Ivan Grozny (Iván el Terrible) se puede rastrear el significado dramático complementando o acentuando a los personajes, las acciones, los diálogos, la música.

Una impronta que ha sido recogida por cineastas posteriores como Kubrick, quien, por ejemplo, desarrolló en la secuencia final "Júpiter: y más allá del infinito" de 2001. A Space Odissey (2001. Una odisea del espacio, 1968) una sublime propuesta audiovisual basada en imágenes psicodélicas, plagada de primeros planos del protagonista junto a paisajes de colores desconcertantes, y la densa composición orquestal Atmosphères de György Ligeti. También realizadores actuales como Nicolas Winding Refn demuestran la solvencia de la propuesta de Eisenstein al unificar en igualdad de condiciones el empleo de 
imagen y sonido con fines dramáticos. En este sentido en The neon Demon (El demonio de neón, 2016) Winding Refn lleva a la práctica la misma propuesta de Eisenstein al organizar, en la secuencia de la discoteca, una hábil narración en la que la música electrónica de Cliff Martínez anticipa, al igual que propusiera el cineasta soviético, los acontecimientos.

En definitiva, las propuestas estéticas de Eisenstein perviven y se perpetúan en las realizaciones cinematográficas actuales. La razón no es otra que la acertada visión que tuvo el cineasta ruso al considerar el cine como una suma de artes y las numerosas propuestas teóricas y prácticas que realizó a lo largo de su vida y que dejó como un legado que debe ser estudiado, visionado y empleado de manera insistente.

\section{Referencias bibliográficas}

Aumont, J. - Marie, M. (1990). Análisis del film. Barcelona: Paidós.

Aumont, J. (1985). Estética del cine. Espacio fúlmico, montaje, narración, lenguaje. Barcelona: Paidós.

Ballò, J. (2000). Imágenes del silencio. Los motivos visuales en el cine. Barcelona: Anagrama.

Bordwell, D. (1996). La narración en el cine de ficción. Barcelona: Paidós.

Bordwell, D. (1999). El cine de Eisenstein. Barcelona: Paidós.

Bresson, R. (1979). Notas sobre el cinematógrafo. México: Era.

De Micheli, M. (2001). Las vanguardias artísticas del siglo XX, Madrid: Alianza Editorial.

Dumas, A. (2018). La mise en scène théâtrale de Eisenstein. París. Il était une fois le cinema. http://www.iletaitunefoislecinema.com/chronique/1945/la-mise-enscene-theatrale-de-eisenstein

Eisenstein, S. M. (Junio - julio 1923). Montaje de atracciones. LEF, (3). Pp. 70-75.

Eisenstein, S. M. (1982). Film essays and a lecture. Princeton: Princeton University Press.

Eisenstein, S. M. (1986). La forma del cine, Buenos Aires: S.XXI.

Eisenstein, S. M. (1990, septiembre). El cine. En La perestroika en el cine. Notas para un ensayo. Cine y más (70), p. 303.

Eisenstein, S. M. (1999). El sentido del cine. México: Siglo XXI. 
Golomostock, I. (1991). L'art totalitaire. Union soviétique-III Reich-Italie fasciste-Chine, Paris: Éditions Carré.

Goodwin, J. (1995). Eisenstein, Cinema and History. Chicago: University of Illinois.

Kandinsky, W. (2001). De lo espiritual en el arte. Barcelona: Paidós.

Lenin, V. I. (1975). Sobre arte y literatura. Madrid: Júcar.

Sadoul, G. (1967). Historia del cine mundial. México: Siglo XXI.

Vertov, D. (1973). El cine ojo. Madrid: Fundamentos. 